\title{
The Need for Delight in Online Education Materials
}

\author{
Adam Procter \\ Winchester School of Art \\ University of Southampton \\ Park Avenue \\ Winchester \\ Hampshire \\ SO23 8DL \\ adam.procter@soton.ac.uk
}

\begin{abstract}
With the demand for online learning materials ever increasing and with more content being made open and free, Higher Education Institutes are now in a position to take their robust virtual learning environments and shift focus from content to user. The new objective being to provide a Delightful user experience that will not only surprise and excite but will improve education online.
\end{abstract}

User Experience, Design, Open Education, Online, User Interface, Users.

\section{INTRODUCTION}

The demand for online learning has been on the increase over recent years as numerous studies have shown. [1]

In response to this upsurge there has also has been an increase in online education web services such as the TED[2] talks, Khan Academy[3] and the P2P University[4] providing both as free and open education.

As this shift for the learner becomes apparent Higher Education Institute's (HEI) now need to embrace open education and become leaders in providing materials that are both engaging and necessary to encourage life long learning.

In Aarron Walters book 'Designing for Emotion'[5] he translates Maslow's Hierarchy of Humans Needs to the needs of an online user, (Figure1) and suggests that many user interface designs are Usable or Edible but not Delightful.

"Simple and usable is great, but there's still more we can achieve. We must bring web design back into the realm of delight." [5]

\section{ONLINE HIGHER EDUCATION MATERIALS}

It can be suggest that Higher Education Institutes (HEI) are in the same position with their online material in most part if not in all. Most are usable and the content is of a high standard, but HEl's need to address the need to add pleasure and Delight to engage the online learner.

A lecturer must be engaging to ensure the content they deliver is understood allowing the learner to act upon this information. Books with an engaging tone of voice can ensure that even the most mudane of materials is understood. Often this can be achieved by providing humour, surprise and Delight. Learning online is often an activity undertaken alone and by the nature of it being via a computer often devoid of personality.

\footnotetext{
"'Rhetoric is the art of discourse, an art that aims to improve the facility of speakers or writers who attempt to inform, persuade, or motivate particular audiences in specific situations."[6]
}

I have not found for my part any current HEI online learning environments that offer the learner any of these two basic elements; humour and surprise or put in another way and for the benefit of this presentation summed up in this one word, Delight. Most will present the data in a standardised format of lists and folders (Figure 2). The content will be of high quality yet the presentation does not engage and make effective use of the delivery method.

Course content and delivery styles need to be tailored to the platform. Currently HEl's will use Blackboard, Moodle or a similar product to provide the content, yet these systems offer limited design opportunities and merely act as a repository for the content. 


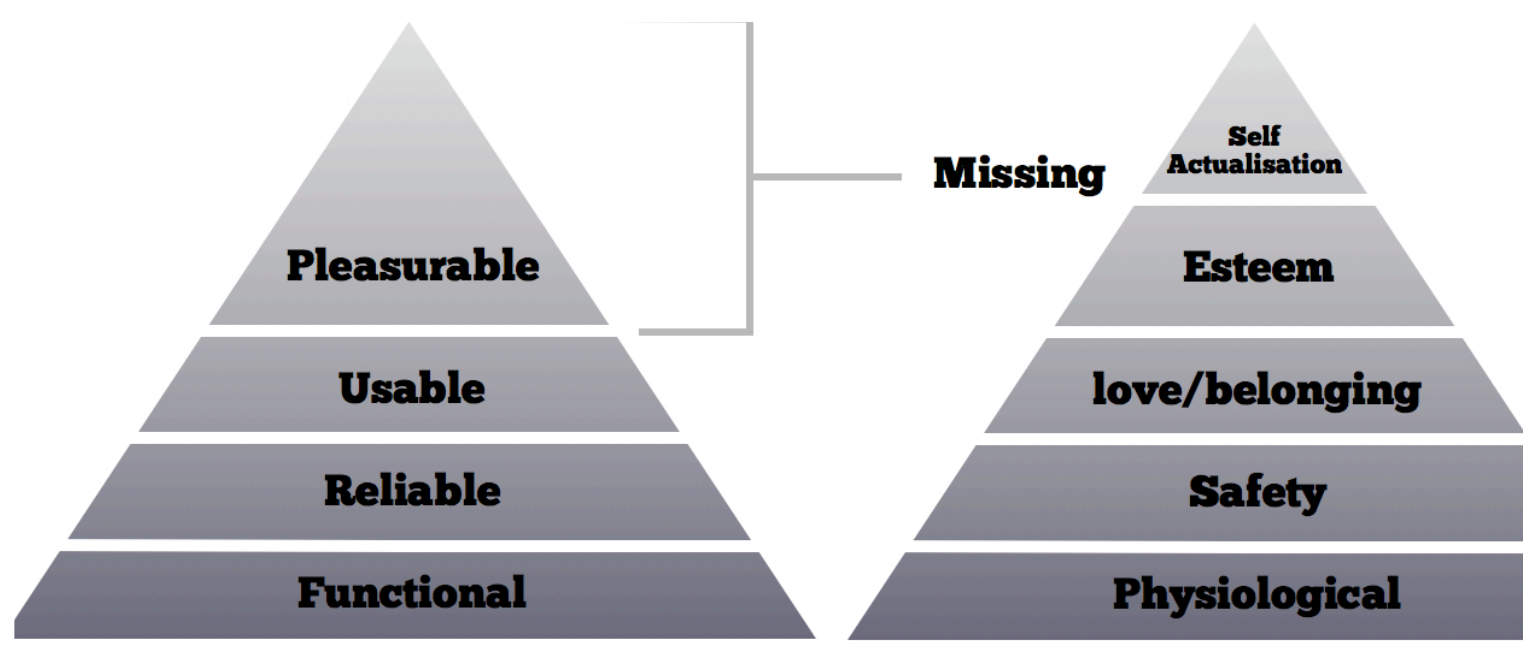

Figure 1: Maslow's Hierarchy of Humans Needs to the needs of a online user

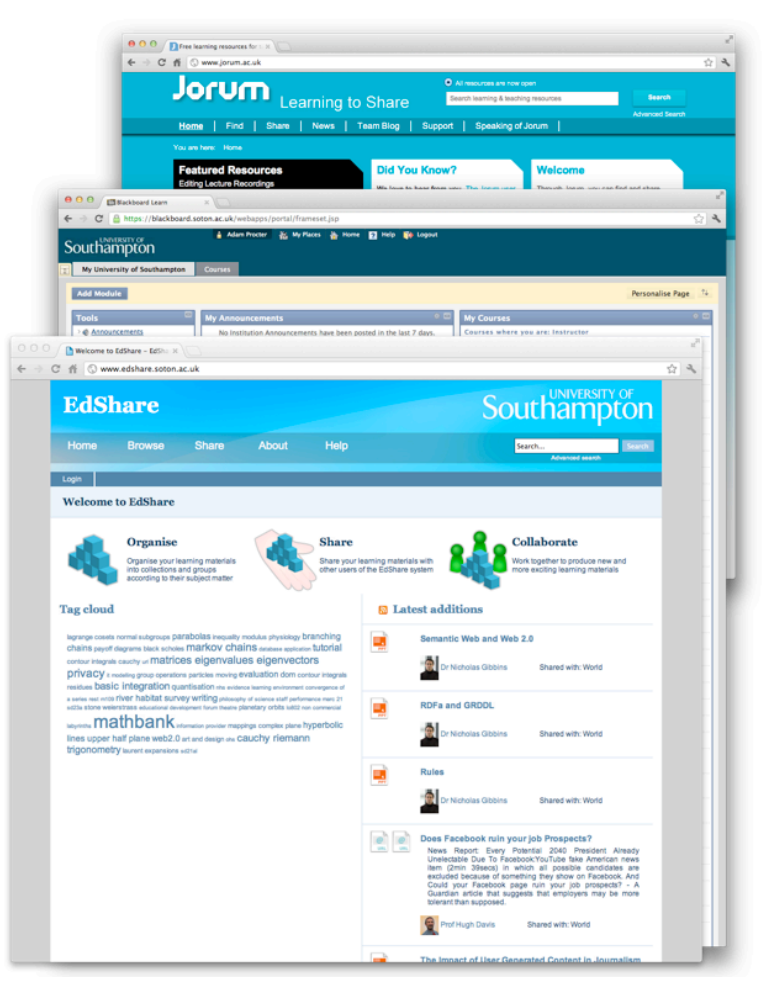

Figure 2: Some HEI Online Education Material sites

As a new media becomes mainstream and is used to deliver information so new opportunities and challenges are opened up to deliver this content in a meaningful and productive way. The material designed for a lecture versus a book versus a TV

Programme has to be adjusted to reflect the viewer's position and relationship to the content.

Within HEl's we are in the position where technology has matured and is both reliable and usable. We need to take these materials to the next phase and should be looking to encourage and Delight our learners. To state the obvious humans are not Robots and a passive engagement with a list of PDFs is not conducive to maximum learning with in the online environment.

\section{DESIGNING FOR DELIGHT}

Even some of the most tedious and tiresome tasks can become a pleasure to do when the interactions and the users position are thoughtfully considered during the design process.

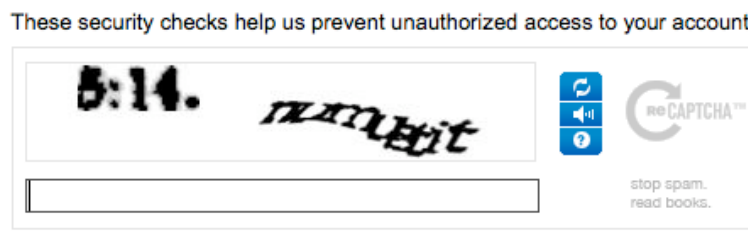

Type the two words separated by a space (not case sensitive).

Figure 3: Re-Capture

Take one online example, (Figure 3). To complete an online form you are often asked to prove you are human this is quite often done via the functional and well know re-capture system, yet the design to confuse a spambot so often also frustrates the user. However a simple redesign of this process can provide Delight and usability. (Figure 4)

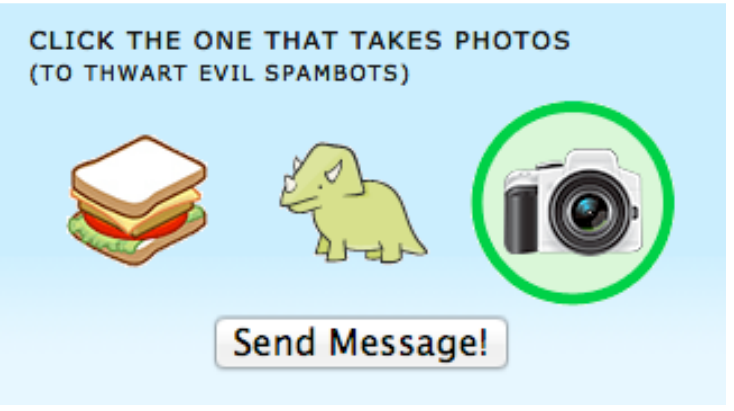

Figure 4: Photojojo's verification question 
Here we see asking you to select the object you would use to take a photo with uses humor, users may well smile at the idea of trying to use a sandwich or a dinosaur as a camera.

By empowering your user you can make them feel good. Aral Balkan describes this as the 'Superman' Effect', because you make the user feel like they were 'Superman'.

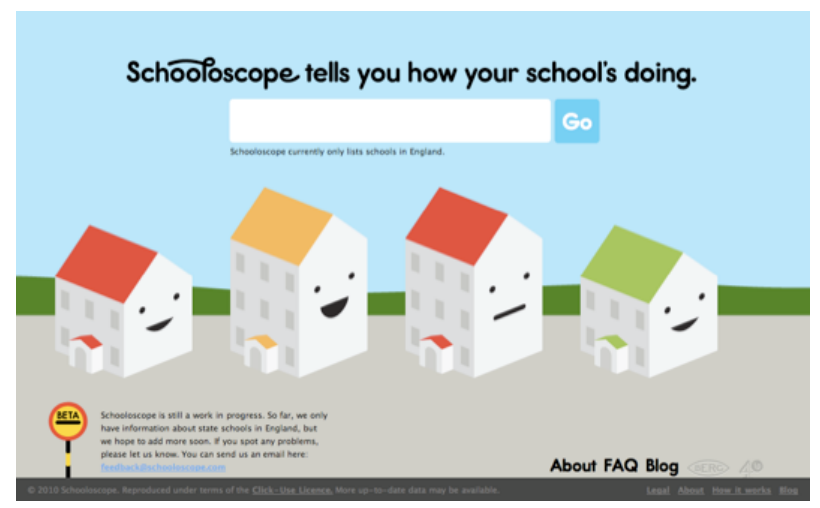

Figure 5: Schooloscope

Another example of incorporating delight online is Schooloscope, which was designed to help parents find out information about school rankings. Ofsted report data is created from School Inspections to create this ranking system. This data direct from Ofsted is of great value but the format can be hard to decipher.

"Schooloscope attempts to bring simplicity, familiarity, and meaning to government education data, for every parent in England." [7]

By converting the data into a cartoon school house and representing the data via varying colour and facial expressions (Figure 6) the undecipherable becomes delightful and with such an emotive decision to make, anxiety over the data is removed.

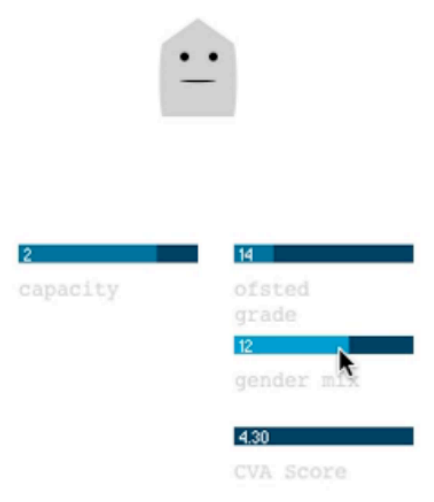

Figure 6: Data conversion

\section{FOR ONLINE EDUCATIONAL MATERIALS}

If we think about applying the same type of design detail for online educational materials we would want to ask how many more fans will you see engaging with the same material? How much more motivation will you see from your learners. How much more effective will your 'teaching' online be?

Mozilla's Openbadges [8] is a framework for anyone to use that allows you to create and issues badges that recognize a specific skill. The concept of badges is not new, however using this concept in online learning has the potential to motivate participation by providing feedback, milestones and rewards throughout a course or learning experience, encouraging engagement and retention.

Increasingly, offline courses are recognising the need to provide learners with more than just learning material - the need to offer a 'learning experience' aimed at that inspiring learners and leaving a lasting impression, thus potentially motivating learning. There is even more potential to achieve this aim in online courses.

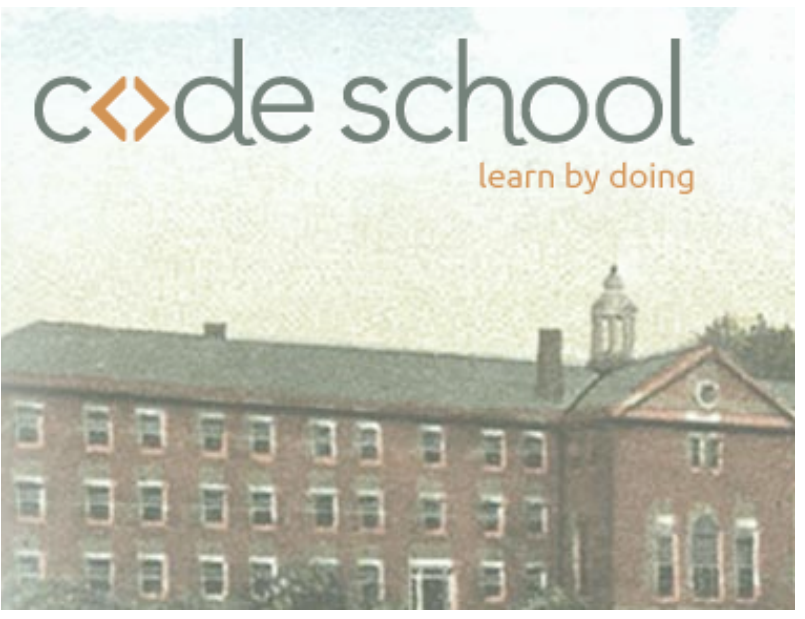

Figure 7: Codeschool.com

The site Code School (Figure 7) appears to have been designed around the notion of providing a Delightful experience to users. Their strap line is 'learn by doing'. Code School combines video instruction, coding in the browser and gamification to help you learn programming. A typical course contains 5 levels, each with a 10-15 minute video followed by series of code challenges a student must solve to make it to the next level. Level completion is rewarded via badges and once complete each course provides additional rewards normally in the form of extra tuition. Each course is given a personality and theme that is often laced with humour.

One such course on Code School is to learn Node.js here you are going to need to understand a 
technical and server-based JavaScript programming language.

\begin{abstract}
"'Node.js is a platform built on Chrome's JavaScript runtime for easily building fast, scalable network applications. Node.js uses an event-driven, non-blocking I/O model that makes it lightweight and efficient, perfect for dataintensive real-time applications that run across distributed devices." [9]
\end{abstract}

The intro to the Node.js training starts with a humorous song in a 'Billy Bragg' style with simple animated graphics representing network traffic. (Figure 8) It is a Delightful surprise and could be considered a novel way to introduce server side programming. This instantly gives the learner a smile and puts them at their ease.

"Your online application is starting to fail. Its crawling on the network, just as fast as a snail, We need evented programming starting from the top. Better write some code so the world doesn't stop!" [10]

Each course is personalised and designed differently to engage the learner via surprise and Delight.

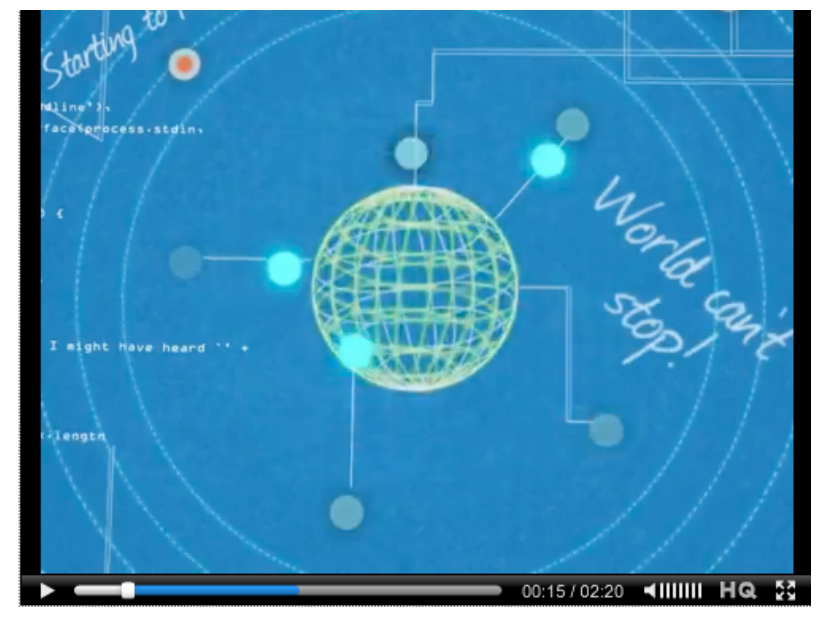

Figure 8: Node.js Training
$\mathrm{HEI}$ online learning materials could gain from applying such techniques and ideas to move beyond focusing on the technology and start to focus on the user and how to enthral and Delight them.

An open discussion on how to bring together online $\mathrm{HEI}$ platform developers with user interface designers could help provide this next level of online learning materials.

"The real payoff comes when we can make that remarkability last. When we can make people continually feel our work is worthy of discussion. When for weeks, months, maybe even years the people who engage with our work continue to sing its praises to everybody they meet." [5]

\section{REFERENCES}

[1] Burnsed, B. (2011) Online Education May Transform Higher Ed, http://bit.ly/QpF7so (Retrieved: 03/08/2012).

Little, R. (2011) Study: Online Education Continues Growth, http://bit.ly/KOknuA (Retrieved: 03/08/2012)

[2] http://www.ted.com/talks

[3] http://www.khanacademy.org/

[4] https://p2pu.org/en/

[5] Author's Walter, A. (2012) Designing for Emotion. A Book Apart, New York.

[6] Multiple Authors. (2012) http://bit.ly/OBhspE (Retrieved: 03/08/2012)

[7] Webb, M. (2010) Say Hello to Schooloscope, http://bit.ly/NTQUBo (Retrieved: 03/08/2012)

[8] http://www.openbadges.org

[9] http://nodejs.org

[10] Allam, E. (2012), http://bit.ly/QrwXRT (Retrieved: 03/08/2012) 